\title{
Analisis Pencemaran Udara Dan Kebisingan Serta Persepsi Masyarakat Tentang Pembangkit Listrik Tenaga Diesel Kota Bitung
}

\author{
B. L. Tampang ${ }^{1}$ \\ Universitas Negeri Manado \\ e-mail: bltampang@unima.ac.id
}

\begin{abstract}
ABSTRAK
Penelitian ini bertujuan: (1) menganalisis tingkat pencemaran udara yang diakibatkan oleh Pembangkit Listrik Tenaga Diesel Kota Bitung. (2) menganalisis tingkat kebisingan yang diakibatkan oleh Pembangkit Listrik Tenaga Diesel Kota Bitung. (3) menganalisis hubungan antara karakteristik masyarakat yang meliputi: umur, pendidikan, pekerjaan, penghasilan, jarak tempat tinggal, dan lama tinggal dengan persepsi masyarakat tentang pencemaran udara dan kebisingan Pembangkit Listrik Tenaga Diesel Kota Bitung. Hasil penelitian menyimpulkan bahwa: (1) Kualitas udara untuk parameter $\mathrm{SO}_{2}, \mathrm{NO}_{2}, \mathrm{H}_{2} \mathrm{~S}, \mathrm{NH}_{3}$ dan $\mathrm{CO}$ menunjukkan bahwa seluruhnya berada di bawah ambang batas baku mutu kualitas udara ambien. Sedangkan debu pada titik A, E, dan J berada di atas ambang batas baku mutu kualitas udara. (2) Tingkat kebisingan sebagai dampak dari kegiatan PLTD Bitung diperoleh bahwa di seluruh lokasi pengukuran pada jarak $100 \mathrm{~m}$ ke bawah telah melewati ambang batas baku mutu kebisingan yang diperbolehkan. (3) Faktor latar belakang sosial masyarakat, yaitu umur, dan lama tinggal dengan sumber pencemaran secara signifikan mempunyai hubungan dengan persepsi masyarakat tentang pencemaran udara. Demikian juga dengan jarak rumah dengan sumber kebisingan secara signifikan mempunyai hubungan dengan persepsi masyarakat tentang kebisingan. Berdasarkan hasil tersebut, maka disarankan supaya: (1) Pemerintah bertindak sebagai penyuluh tentang lingkungan yang efektif. Selanjutnya perlu penataan kembali kawasan pemukiman dan kawasan industri dengan memperhatikan kelurahan Bitung Tengah sebagai pemukiman penduduk, sehingga sebaiknya PLTD berjarak minimal $100 \mathrm{~m}$ dari pemukiman penduduk. (2) Dalam upaya menurunkan tingkat kebisingan, hendaknya menanam pohon di kawasan PLTD, antara lain pohon bambu kuning dan pohon cemara laut yang berfungsi sebagai peredam bunyi, juga dapat menambah keindahan.
\end{abstract}

Kata kunci: Pencemaran Udara, Kebisingan, Persepsi, PLTD

\section{ABSTRACT}

This study aims: (1) to analyze the level of air pollution caused by Diesel Power Plant (PLTD) of Bitung City. (2) to analyze the noise level caused by PLTD of Bitung City. (3) to analyze the correlation between the characteristics of the society which include: age, education, occupation, income, distance of residence, and length of stay with public perception about air pollution and

Jurnal Frontiers Volume 1 Nomor 1, April 2018119

P-ISSN: 2621-0991 E-ISSN: 2621-1009 
noise of PLTD of Bitung City. The results of the study concluded that: (1) Air quality for $\mathrm{SO} 2, \mathrm{NO} 2, \mathrm{H} 2 \mathrm{~S}, \mathrm{NH} 3$ and $\mathrm{CO}$ parameters showed that it was all below the ambient quality standard. While the dust at point A, E, and $J$ is above the standard quality air quality threshold. (2) The noise level as a result of the Bitung PLTD activity is obtained that in all the measuring sites at a distance of $100 \mathrm{~m}$ down has crossed the permitted noise quality standard threshold. (3) The social background factors of the community, ie age, and length of stay with pollution sources are significantly related to the public perception of air pollution. Likewise, the distance of houses with noise sources is significantly related to people's perception of noise. Based on these results, it is recommended that: (1) The Government acts as an effective environmental counselor. Furthermore, it is necessary to rearrange residential area and industrial area by paying attention to Bitung Tengah urban village as residential area, so that PLTD should be at least $100 \mathrm{~m}$ from residential area. (2) In order to reduce the noise level, plant trees in PLTD areas, including yellow bamboo trees and sea pine trees that serve as silencers, also can add beauty.

\section{Keywords: Air Pollution, Noise, Perception, PLTD}

\section{PENDAHULUAN}

Pencemaran udara diartikan adanya atau masuknya satu atau lebih zat pencemar atau kombinasinya di atmosfer dalam jumlah dan waktu tertentu baik yang masuk ke udara secara alami maupun akibat aktivitas manusia, yang dapat menimbul-kan gangguan pada manusia, hewan, tumbuhan dan terhadap harta benda atau terganggunya kenyamanan dan kenikmatan hidup dan harta benda (KLH, 1987; World Bank, 1988; Canter, 1997). Dengan semakin meningkatnya perkembangan industri, baik industri migas, pertanian, maupun industri nonmigas lainnya, maka semakin meningkat pula tingkat pencemaran udara yang disebabkan oleh hasil buangan industri-industri.

Hal tersebut, sesuai dengan pendapat Wardana (2004) yang menyatakan kegiatan industri dan teknologi dapat memberikan dampak lingkungan, baik secara langsung maupun tidak langsung. Dampak langsung, antara lain berupa: (a) pencemar-an lingkungan akibat bahan buangan atau sisa industri yang dapat mengotori udara, air, dan tanah; (b) kebisingan kontinyu maupun impulsif yang dapat menimbulkan penyakit; (c) lingkungan menjadi tidak nyaman untuk pemukiman; (d) pandangan yang kurang sedap di daerah industri. Dampak tak langsung, antara lain: (a) urbanisasi, (b) perubahan nilai sosial budaya.

Dari semua sektor pembangunan selalu mengarahkan supaya selalu mempunyai keselarasan, keserasian, dan keseimbangan, baik kepada Tuhan, sesama manusia maupun dengan lingkungan hidupnya, sehingga dalam melaksanakan pembangunan tidak boleh lepas dari ketiga unsur tesebut. Pada dasarnya permasalahan lingkungan ada, karena ketidakseimbangan eksosistem, akibat intervensi terhadap lingkungan, sehingga keseimbangan lingkungan menjadi terganggu. Untuk memulihkan atau menjaga keseimbangan tersebut, maka diperlukan pengendalian perilaku manusia dalam memanfaatkan sumberdaya alam, 
termasuk di dalamnya pembangunan industri yang menimbulkan pencemaran air, tanah, dan udara, serta faktor kebisingan.

Kebijakan pembangunan yang berwawasan lingkungan antara lain ditetapkan untuk mengembangkan sumberdaya manusia agar mampu menanggapi tantangan pembangunan tanpa merusak lingkungan, yaitu dengan mengembangkan kesadaran lingkungan di kalangan masyarakat, sehingga tumbuh menjadi kesadaran berbuat (Salim, 2006).

Kenyataan membuktikan bahwa sampai saat ini, masih terdapat berbagai kekurangan dalam upaya pembangunan yang memerlukan perhatian dan juga berbagai upaya perbaikan dalam pelaksanaannya. Berbagai kekurangan tersebut, menurut Salim (2006) bahwa pola pembangunan industri menggunakan modal yang makin banyak didorong oleh kemajuan teknologi. Pola tersebut, mengakibatkan tekanan pada sumberdaya alam yang makin besar dalam waktu yang makin singkat. Dengan demikian lingkungan buatan manusia makin besar dan mendesak lingkungan alam. Sungguhpun teknologi mengalami kemajuan pesat, tetapi dalam perkembangannya tidak seluruhnya mampu menggantikan fungsi lingkungan alam. Hal tersebut, menimbulkan ketimpangan yang lebih jauh mengakibatkan kemerosotan kualitas lingkungan, antara lain: (a) timbulnya pencemaran lingkungan oleh bahan beracun berbahaya (B3) serta limbah lainnya, (b) tercemarnya kebutuhan vital: tanah, air, udara dengan berbagai bahan pencemar baik kimia, fisik, maupun hayati, termasuk hujan asam, kenaikan kadar $\mathrm{CO}_{2}$, kenaikan suhu atmosfer dan sebagainya

Salah satu sumber pencemar udara dan kebisingan adalah Pembangkit Listrik
Tenaga Diesel (PLTD). Pada mesin tenaga diesel zat-zat yang terkandung dalam bahan bakar yang mempengaruhi pengoperasian mesin diesel antara lain: (a) Arang atau karbon: Banyaknya siswa karbon yang tidak terbakar membuktikan bahwa pembakaran tidak sempurna. Hal tersebut, selain mempengaruhi nilai kalor yang dihasilkan selama proses pembakaran, juga menyebabkan jelagu atau endapan karbon di ruang bakar atau menyebabkan kotoran minyak pelumas; (b) Sediment (pengendapan) dan Sludge: Sedimen dan Sludge akan mengendap pada dasar tanki bahan bakar, yang akan menyebabkan korosi di dasar tanki, menyumbat filter atau separator. Makin lama minyak, makin banyak sediment dan sludge terbentuk; (c) Air: Air akan mempengaruhi warna minyak, karena air mudah melarut zat lain, sehingga minyak mudah kotor, air dapat menyebabkan korosi terutama di bagian dasar tanki; (d) Sulfur atau belerang: Kandungan sulfur atau belerang dalam bahan bakar minyak biasanya antara $0,2-4 \%$. Kandungan belerang yang tinggi akan mempengaruhi: (1) kenaikan titik emben gas buang, kecepatan pembentukan kerak sulfat, (3) kecepatan korosi, (4) kecepatan pembentukan sludge dan sediment dalam penyimpangan. (e) Abu: Pada umumnya abu dalam bahan bakar minyak (residu) sangat rendah, tetapi unsur pembentukan abu seperti natrium dan vanadium perlu mendapatkan perhatian, karena kedua unsur tersebut menyebabkan korosi dan erosi di ruang bakar. Abu natrium dan vanadium mempunyai titik leleh yang rendah $\left(600-900^{\circ}\right)$, sehingga biasanya kedua unsur tersebut menyebabkan erosi dan korosi pada (temperatur tinggi, PLN, 2006).

Di Provinsi Sulawesi Utara, Kota Bitung adalah kota terbesar kedua setelah Kota Manado; kota pelabuhan terbesar 
kedua di Kawasan Timur Indonesia setelah pelabuhan Makassar, dan kota industri yang berpotensi mempunyai tingkat pencemaran udara dan kebisingan yang cukup tinggi. PLTD yang terletak di tengah-tengah Kota Bitung telag beroperasi sejak Tahun 1977, dianggap dapat mewakili kondisi produsen pencemaran udara dan kebisingan yang khas dalam suatu kota industri.

Berdasarkan uraian tersebut, maka penelitian tentang pencemaran udara dan kebisingan sumber energi diesel di PLTD Kota Bidung dapat memberikan gambaran mengenai tingkat pencemaran udara dan kebisingan yang diakibatkan oleh sumber energi tersebut, dan persepsi masyarakat yang ada di sekitar PLTD. Dari latar belakang masalah tersebut, maka masalah penelitian ini dapat dirumuskan sebagai berikut:

a. Seberapa besar tingkat pencemaran udara yang diakibatkan oleh Pembangkit Listrik Tenaga Diesel Kota Bitung.

b. Seberapa besar tingkat kebisingan yang diakibatkan oleh Pembangkit Listrik Tenaga Diesel Kota Bitung.

c. Seberapa besar hubungan antara karakteristik masyarakat yang meliputi: umur, pendidikan, pekerjaan, penghasilan, jarak tempat tinggal, dan lama tinggal dengan persepsi masyarakat tentang pencemaran udara dan kebisingan Pembangkit Listrik Tenaga Diesel Kota Bitung.

Tujuan penelitian ini adalah

a. Untuk menganalisis tingkat pencemaran udara yang diakibatkan oleh Pembangkit Listrik Tenaga Diesel Kota Bitung.

b. Untuk menganalisis tingkat kebisingan yang diakibatkan oleh Pembangkit Listrik Tenaga Diesel Kota Bitung.

c. Untuk menganalisis hubungan antara karakteristik masyarakat yang meliputi: umur, pendidikan, pekerjaan, penghasilan, jarak tempat tinggal, dan lama tinggal dengan persepsi masyarakat tentang pencemaran udara dan kebisingan Pembangkit Listrik Tenaga Diesel Kota Bitung.

\section{METODE}

Jenis penelitian ini adalah penelitian deskriptif. Dalam penelitian ini bahan dan alat yang digunakan di lapangan adalah: (1) satu buah peta administrasi Kelurahan Bitung Tengah, (2) sound level nmeter, (3) kuesioner.

Jenis data yang dikumpulkan terdiri dari dua macam data, yaitu data primer dan data sekunder. Data primer untuk pencemaran udara diperoleh dari beberapa hasil penelitian terdahulu (karena pemantauan atau penelitian pada PLTD Kota Bitung secara rutin dilaksanakan setiap satau semester), sesuai dengan Rencana Pemantauan Lingkungan (RPL) yang telah disetujui pemerintah. Data primer untuk kebisingan dikumpulkan dengan menggunakan alat sound level meter. Sedangkan data primer mengenai persepsi masyarakat tentang pencemaran udara dan kebisingan PLTD Kota Bitung diperoleh dengan cara mengedarkan kuesioner, wawancara kepada responden, serta pengamatan langsung di lokasi penelitian.

Data sekunder diperoleh dari beberapa instansi terkait, seperti: BLH Provinsi Sulut, BLH Kota Bitung, PT. PLN (Persero) wilayah VII Sektor Minahasa, Kantor Kelurahan Bitung Tengah, Puskesmas Kecamatan Bitung Tengah, serta informasi lainnya seperti tokoh-tokoh masyarakat di lokasi penelitian.

Pemilihan responden sebagai unit penelitian dilakukan dengan metode penarikan sampel secara Cluster Random Sampling (Arikunto, 2004; Tampang, 2012), yaitu populasi dibagi dulu atas 
kelompok berdasarkan area atau cluster. Anggota subpopulasi tiap cluster tidak perlu homogen. Beberapa cluster dipilih terlebih dahulu sebagai sampel, kemudian dipilih lagi anggota unit dari sampel cluster.

Untuk tujuan penelitian pertama, dianalisis dengan cara membandingkan hasil pengukuran atau penelitian terhadap baku mutu udara ambien yang dikeluarkan oleh Menteri Negara Lingkungan Hidup Nomor:Kep.02/MENKLH/I/1988. Analisis tersebut digunakan untuk memberikan penjelasan secara deskriptif terhadap data yang diperoleh.

Untuk tujuan penelitian kedua, dianalisis dengan rumus:

$\mathrm{L}_{\mathrm{S}}$ dihitung sebagai berikut:

$\mathrm{L}_{\mathrm{S}}=10 \log 1 / 16\left[\mathrm{~T} 1.10^{0.1 \mathrm{~L} 1}+\ldots+\mathrm{T} 4.10^{0.1 \mathrm{~L} 4}\right] \mathrm{dB}(\mathrm{A})$

$\mathrm{L}_{\mathrm{M}}$ dihitung sebagai berikut:

$\mathrm{L}_{\mathrm{M}}=10 \log 1 / 8\left[\mathrm{~T} 5.10^{0.1 \mathrm{~L} 5}+\ldots+\mathrm{T} 7.10^{0.1 \mathrm{~L} 7}\right] \mathrm{dB}(\mathrm{A})$

Untuk mengetahui apakah tingkat kebisingan sudah melampaui baku mutu tingkat kebisingan yang dikeluarkan oleh Menteri Negara Lingkungan Hidup Nomor:Kep-48/MENLH/11/1996, maka perlu dicari $\mathrm{L}_{\mathrm{SM}}$ dari pengukuran lapangan. $\mathrm{L}_{S M}$ dihitung dengan rumus:

$\mathrm{L}_{\mathrm{SM}}=10 \log 1 / 24\left[16.10^{0.1 \mathrm{LS}}+8.10^{0.1(\mathrm{LM}+5)}\right] \mathrm{dB}(\mathrm{A})$

Nilai LSM yang dihitung dibandingkan dengan nilai baku mutu tingkat kebisingan yang ditetapkan dengan toleransi +3 dB(A), MENLH, 1997).

Untuk tujuan penelitian ketiga, dianalisis dengan teknik analisis Kai Kuadrat (Chi-Square) dari (Siegel, 1995, Sudjana, 2006) dengan rumus:

$$
x^{2}=\sum_{i=1}^{k} \frac{\left(0_{i}-E_{i}\right)^{2}}{E_{i}}
$$

Keterangan:

$\mathrm{O}_{\mathrm{i}}=$ frekuensi yang diamati, kategori ke-i

$\mathrm{E}_{\mathrm{i}}=$ frekuensi yang diharapkan dari populasi ke-i

$\mathrm{k}=$ jumlah sampel

Kriteria pengujian adalah tolak Ho jika $X^{2} \geq X^{2}(1-\alpha)(\mathrm{k}-1)$ dengan $\alpha=$ taraf nyata untuk pengujian. Dalam hal lainnya Ho diterima.

Untuk menguji tingkat keeratan hubungan antara kedua peubah digunakan rumus koefisien kontingensi pearson (Siegel, 1995)

$$
C=\sqrt{\frac{x^{2}}{N+x^{2}}}
$$

Keterangan:

$$
\begin{gathered}
\mathrm{x}^{2}=\text { nilai Kai-kuadrat } \\
\mathrm{n}=\text { jumlah sampel }
\end{gathered}
$$

\section{HASIL DAN PEMBAHASAN}

Hasil penelitian yang menjawab rumusan masalah yang pertama dijelaskan sebagai berikut. Hasil analisis kualitas Udara di sekitar Pembangkit Listrik Tenaga Diesel Kota Bitung dapat dilihat pada Tabel 1, dari hasil analisis pada menunjukkan bahwa untuk sampel udara pada (titik A, E, dan J) debu berada di atas ambang batas menurut SK. MENKLH No. Kep.02/MENKLH/I/1988, tanggal 19 Januari 1988. Sedangkan untuk parameter $\mathrm{SO}_{2}, \mathrm{NO}_{2}, \mathrm{H}_{2} \mathrm{~S}, \mathrm{NH}_{3}$, dan $\mathrm{CO}$ masih berada di bawah ambang batas. Tingginya kadar debu pada lokasi titik sampel tersebut, diduga disebabkan oleh keadaan fisik tanah di Bitung berpasir yang sedikit relatif berdebu. Selain hal tersebut, juga di daerah lokasi pengambilan sampel udara pada PLTD Bitung merupakan daerah kawasan industri, serta kegiatan-kegiatan lainnya yang berada di daerah PLTD Bitung. Hasil analisis kualitas udara di sekitar PLTD Bitung Tahun 2016 dapat dilihat pada Tabel 1.

Berdasarkan hasil analisis contoh udara yang diambil pada empat titik pengamatan, menunjukkan bahwa seluruhnya berada di bawah ambang batas baku mutu kualitas udara ambien. Pengukuran di pusat kegiatan PLTD diperoleh kandungan $\mathrm{CO}$ sebesar 12,5 ppm, $\mathrm{SO}_{2}$ 0,03 ppm dan $\mathrm{NO}_{2}$ ttd (tidak terdeteksi). Baku mutu udara ambien 
diatur dalam keputusan MENKLH No. Kep.02/MENKLH/I/1988 untuk parameter $\mathrm{CO}$ sebesar $20 \mathrm{ppm}, \mathrm{SO}_{2}$ 0,10 ppm dan $\mathrm{NO}_{2}$ sebesar 0,05 ppm. Khususnya di pemukiman sebelah Barat, pemukiman sebelah Timur, dan pemukiman sebelah Utara diperoleh kandungan $\mathrm{CO}, \mathrm{CO}_{2}$ dan $\mathrm{NO}_{2}$ udara bebas tidak terdeteksi.

Hasil penelitian yang menjawab rumusan masalah yang kedua dijelaskan sebagai berikut. Kebisingan yang diakibatkan oleh kegiatan PLTD Bitung diukur selama 24 jam $\left(\mathrm{L}_{\mathrm{dn}}\right)$ dengan cara pada siang hari tingkat aktifitas yang paling tinggi selama 16 jam $\left(\mathrm{L}_{\mathrm{d}}\right)$ pada selang waktu 06.00 - 22.00 dan aktifitas malam hari selama 8 jam $\left(\mathrm{L}_{\mathrm{h}}\right)$ pada selang waktu $22.00-06.00$. Pengukuran dilakukan pada jarak (a) $\leq 50 \mathrm{~m}$, (b) $50-$ $100 \mathrm{~m}$, (c) $\geq 100 \mathrm{~m}$, yaitu pada lokasi: (1) dalam ruangan atau pusat kegiatan, (b) luar ruangan, (3) pertokoan, (4) pemukiman sebelah Barat, (5) Pemukiman sebelah Timur, dan (6) Pemukiman sebelah Utara. Hasil analisis tingkat kebisingan $\mathrm{L}_{\mathrm{d}}, \mathrm{L}_{\mathrm{n}}$, dan $\mathrm{L}_{\mathrm{dn}}$ PLTD Bitung dapat dilihat pada Tabel 2 .
Hasil analisis pengukuran tingkat kebisingan sebagai dampak dari kegiatan PLTD Bitung diperoleh bahwa seluruh lokasi pengamatan pada jarak $100 \mathrm{~m}$ ke bawah telah melewati ambang batas baku mutu kebisingan yang diperbolehkan, yaitu sebesar 70 dBA untuk kawasan industri, $55 \mathrm{dBA}$ untuk perumahan dan pemukiman, dan $70 \mathrm{dBA}$ untuk kawasan perdagangan dan jasa, yang diatur dalam Kep.48/MENKLH/11/1996 tanggal 25 November 1996. Tingkat kebisingan di pusat kegiatan PLTD (dalam ruangan) berkisar 98,4-103,7 dBA, di luar ruangan PLTD berkisar 87,9 - 74,8 dBA, pemukiman sebelah Barat berkisar 77,2 81,5 dBA, pemukiman sebelah Timur berkisar 75,5 - 77,8 dBA, pemukiman sebelah Utara berkisar 46,5 - 51,5 dBA. Khusus pada pemukiman sebelah Barat dan pertokoan, nampaknya tingkat kebisingan tidak hanya disebabkan oleh kegiatan PLTD Bitung, melainkan juga oleh kegiatan dari PLTD Trakindo.

Tingkat kebisingan di sekitar PLTD Bitung pada jarak $100 \mathrm{~m}$ ke bawah sudah melampaui ambang batas tingkat kebisingan untuk pemukiman.

Tabel 1 Hasil Analisis Kualitas Udara PLTD Bitung Tahun 2016

\begin{tabular}{|c|c|c|c|c|c|c|c|c|c|c|c|}
\hline \multirow[b]{2}{*}{ Parameter } & \multirow[b]{2}{*}{ Satuan } & \multicolumn{10}{|c|}{ Konsentrasi } \\
\hline & & A & B & $\mathrm{C}$ & $\mathrm{D}$ & $\mathrm{E}$ & $\mathrm{F}$ & $\mathrm{G}$ & $\mathrm{H}$ & I & $\mathrm{J}$ \\
\hline \multicolumn{12}{|l|}{$\begin{array}{l}\text { Sulfur dioksida } \\
\left(\mathrm{SO}_{2}\right)\end{array}$} \\
\hline$\left(\mathrm{SO}_{2}\right)$ & ppm & 0.019 & 0.002 & 0.036 & 0.020 & 0.091 & 0.045 & 0.009 & 0.017 & 0.038 & 0.092 \\
\hline Oksida & ppm & 0.046 & 0.48 & 0.029 & 0.031 & 0.046 & 0.037 & 0.049 & 0.036 & 0.048 & 0.053 \\
\hline nitrogen $\left(\mathrm{NO}_{2}\right)$ & ppm & 0.028 & 0.025 & 0.013 & 0.027 & 0.031 & 0.011 & 0.024 & 0.015 & 0.032 & 0.018 \\
\hline Hidrogen & ppm & 0.411 & 0.120 & 0.020 & 0.014 & 0.71 & 0.04 & 0.014 & 0.007 & 0.011 & 0.079 \\
\hline Sulfida $\left(\mathrm{H}_{2} S\right)$ & $\mathrm{ppm}$ & 9.190 & 10.120 & 11.710 & 9.150 & 8.170 & 11.680 & 8.760 & 9.690 & 10.140 & 22.780 \\
\hline Amoniak $\left(\mathrm{NH}_{3}\right)$ & $\mathrm{mg} / \mathrm{m}^{3}$ & 1.440 & 0.780 & 0.960 & 0.520 & 1.140 & 0.880 & 0.490 & 0.260 & 0.660 & 3.670 \\
\hline Debu & & & & & & & & & & & \\
\hline
\end{tabular}

Jurnal Frontiers Volume 1 Nomor 1, April 2018124

P-ISSN: 2621-0991 E-ISSN: 2621-1009 
Tabel 2 Hasil Analisis Kualitas Udara PLTD Bitung Tahun 2016

\begin{tabular}{|c|c|c|c|c|c|c|c|}
\hline \multirow[t]{2}{*}{ No. } & \multirow{2}{*}{ Parameter } & \multirow[t]{2}{*}{ Satuan } & \multicolumn{4}{|c|}{ Lokasi Penelitian } & \multirow{2}{*}{$\begin{array}{l}\text { Baku Mutu Udara Ambien } \\
\text { No.Kep. 02/MENKLH/I/1983 }\end{array}$} \\
\hline & & & $\mathrm{I}$ & II & III & IV & \\
\hline 1 & $\mathrm{CO}$ & $\mathrm{ppm}$ & 12,5 & $\mathrm{ttd}$ & $\mathrm{ttd}$ & $\mathrm{ttd}$ & 20 \\
\hline 2 & $\mathrm{SO}_{2}$ & ppm & 0,03 & ttd & ttd & ttd & 0,10 \\
\hline 3 & $\mathrm{NO}_{2}$ & $\mathrm{ppm}$ & ttd & ttd & ttd & $\mathrm{ttd}$ & 0,05 \\
\hline
\end{tabular}

$\begin{array}{ll}\text { Keterangan: } & \begin{array}{l}\text { Lokasi I } \\ \text { Lokasi II }\end{array} \\ \text { Lokasi III } & =\text { Pemukat Kegiatan PLTD Bitung } \\ \text { Loaksi IV } & =\text { Pemukiman Sebelah Barat Timur } \\ \text { Ttd } & =\text { Tidak terdeteksi }\end{array}$

Sarwono (1999), Soeryani, at.al. (2007), dan Soejono (2010) menyatakan faktor sosial ekonomi yang berhubungan dengan persepsi masyarakat, yaitu: umur, tingkat pendidikan, pekerjaan, dan penghasilan. Hasil perhitungan statistik dengan menggunakan analisis statistik Kai-Kuadrat (Chi-Square) (Siegel, 2005, dan Walpole, 2007) menunjukkan faktor sosial ekonomi yang berhubungan dengan persepsi masyarakat tentang pencemaran udara sumber energi diesel (PLTD Bitung) dapat dilihat pada table 3 .

Pada Tabel 3, nilai $\mathrm{X}_{\text {hitung }}^{2}$ Hubungan Umur dengan Persepsi Masyarakat tentang Pencemaran Udara sebesar 32,008 lebih besar daripada $\mathrm{X}_{\text {tabel }}^{2}(20 ; 0,05)=31,4$. Hal tersebut, menunjukkan bahwa umur mempunyai hubungan yang signifikan dengan persepsi masyarakat tentang pencemaran udara. Hubungan tersebut, juga mengungkapkan bahwa perbedaan umur masyarakat menyebabkan perbedaan persepsi mereka tentang pencemaran udara.

Hasil penelitian mengungkapkan umur antara 25 - 55 tahun yang lebih peka daripada umur 25 tahun ke bawah dan umur 55 tahun ke atas.Nilai koefisien kontingensi sebesar 0,5903 menunjukkan bahwa derajad hubungan yang erat antara umur seseorang dengan persepsinya tentang pencemaran udara. Hal tersebut, membuktikan bahwa umur antara $25-55$ tahun yang lebih peka daripada umur 25 tahun ke bawah dan 55 tahun ke atas.

Tabel 3. Hubungan Faktor Sosial Ekonomi dengan Persepsi Masyarakat Tentang Pencemaran Udara

\begin{tabular}{|c|c|c|c|c|c|c|c|c|c|}
\hline \multirow{2}{*}{$\begin{array}{c}\text { Faktor } \\
\text { Sosial } \\
\text { Ekonomi }\end{array}$} & \multirow[t]{2}{*}{ Kategori } & \multicolumn{5}{|c|}{$\begin{array}{c}\text { Persepsi Masyarakat } \\
\text { Tentang Pencemaran Udara }\end{array}$} & \multicolumn{3}{|c|}{ Nilai } \\
\hline & & SK & KTR & TH & $\mathrm{CB}$ & B & $X^{2}{ }_{h t g}$ & $X_{t b l 0.05}^{2}$ & KK \\
\hline \multirow[t]{5}{*}{ Umur } & $<25$ & 0 & 3 & 0 & 1 & 0 & \multirow{5}{*}{ 32.088* } & \multirow{5}{*}{$\begin{array}{c}31.4 \\
\mathrm{db}=20\end{array}$} & \multirow{5}{*}{$0.5903^{+}$} \\
\hline & $25-35$ & 3 & 2 & 2 & 10 & 3 & & & \\
\hline & $36-45$ & 0 & 7 & 3 & 10 & 3 & & & \\
\hline & $46-55$ & 0 & 3 & 2 & 5 & 0 & & & \\
\hline & $56-65$ & 0 & 1 & 0 & 0 & 1 & & & \\
\hline
\end{tabular}

Jurnal Frontiers Volume 1 Nomor 1, April 2018125

P-ISSN: 2621-0991 E-ISSN: 2621-1009 


\begin{tabular}{cccccccccc}
\hline & $>65$ & 1 & 0 & 0 & 0 & 0 & & & \\
\hline Pendidika & SD & 1 & 1 & 0 & 0 & 0 & & & \\
n & SLTP & 1 & 5 & 0 & 9 & 4 & & & \\
& SLTA & 2 & 6 & 5 & 12 & 2 & $18.137^{\text {tr }}$ & 26.3 & 0.4818 \\
& Akademi & 0 & 2 & 2 & 4 & 0 & & $\mathrm{db}=$ & \\
& Universitas & 0 & 2 & 0 & 1 & 1 & & 16 & \\
\hline Pekerjaan & PNS/ABRI & 1 & 2 & 1 & 1 & 0 & & & \\
& Karyawan Swasta & 2 & 9 & 3 & 6 & 2 & & & \\
& Wiraswasta & 0 & 1 & 3 & 14 & 4 & $19.273^{\text {tr }}$ & 26.3 & 0.4931 \\
& Petani/Buruh & 1 & 3 & 0 & 5 & 1 & & $\mathrm{db}=$ & \\
& Pensiunan & 0 & 1 & 0 & 0 & 0 & & 16 & \\
\hline Penghasil & $<100.000$ & 1 & 0 & 0 & 2 & 0 & & & \\
an & $100.000-250.000$ & 1 & 3 & 4 & 13 & 3 & & & \\
& $251.000-350.000$ & 1 & 1 & 2 & 6 & 2 & $24.271^{\text {tr }}$ & 26.3 & 0.5367 \\
& $351.000-500.000$ & 1 & 10 & 1 & 2 & 2 & & $\mathrm{db}=$ & \\
\hline Jarak & $501.000-1$ juta & 0 & 2 & 0 & 3 & 0 & & 16 & \\
Rumah & $<50 \mathrm{~m}$ & 2 & 9 & 2 & 7 & 0 & & & \\
& $50-100 \mathrm{~m}$ & 1 & 5 & 2 & 10 & 2 & $11.373^{\text {tr }}$ & 15.55 & 0.3992 \\
& $>100 \mathrm{~m}$ & 1 & 2 & 3 & 9 & 5 & & $\mathrm{db}=8$ & \\
\hline Lama & $<1$ thn & 3 & 2 & 0 & 3 & 0 & & & \\
Tinggal & $1-5$ thn & 1 & 4 & 5 & 10 & 2 & & & \\
& $6-10$ thn & 0 & 1 & 2 & 8 & 0 & $31.729^{*}$ & 21.0 & $0.5881^{+}$ \\
& $>10$ thn & 0 & 9 & 0 & 5 & 5 & & db $=$ & \\
& & & & & & & & 12 & \\
& & & & & & & &
\end{tabular}

Keterangan:

$\mathrm{SK}=$ Sangat kotor

$\mathrm{KTR}=$ Kotor

$\mathrm{TH}=$ Tidak tahu

$\mathrm{CB}=$ Cukup bersih

$\mathrm{B}=$ Bersih

$\begin{array}{ll}X^{2} & =\quad \text { Kai Kuadrat } \\ \mathrm{KK} \quad & =\text { Koefisien Kontigensi } \\ & \text { tn) } \quad=\text { Tidak nyata dalam taraf } 0,05 \\ *) & =\quad \text { Signifikan pada } \mathrm{p}=0,05\end{array}$

$+)=$ Derajat hubungan erat
Pada Tabel 3, nilai $\mathrm{X}^{2}{ }_{\text {hitung }}$ hubungan Pendidikan dengan Persepsi Masyarakat tentang Pencemaran Udara sebesar 18,137 lebihkecilr daripada $\mathrm{X}_{\text {tabel }}^{2}(16 ; 0,05)=$ 26,3. Hal tersebut, menunjukkan bahwa tingkat pendidikan formal tidak mempunyai hubungan yang signifikan dengan persepsi masyarakat tentang pencemaran udara; artinya tidak ada perbedaan yang nyata antara tingkat pendidikan dengan persepsi masyarakat tentang pencemaran udara. Dengan kata lain, tingkat pendidikan formal tidak mempengaruhi persepsi masyarakat tentang pencemaran udara. Hal tersebut, dapat dimaklumi karena 80,00 \% dari responden yang menempuh tingkat pendidikan SLTA ke bawah, yang tidak mengajarkan materi dasar tentang pencemaran udara. Nilai koefisien kontingensi sebesar 0,4818 menunjukkan derajad hubungan yang kurang erat antara tingkat pendidikan formal dengan persepsi masyarakat tentang pencemaran udara. Hal tersebut, mengungkapkan bahwa tinggi rendahnya pendidikan formal seseorang tidak mempengaruhi persepsinya tentang pencemaran udara.

Pada Tabel 3, nilai $\mathrm{X}^{2}{ }_{\text {hitung Hubungan }}$ pekerjaan dengan persepsi masyarakat tentang pencemaran udara sebesar 19,273 lebih kecil daripada $\mathrm{X}_{\text {tabel }}^{2}(16 ; 0,05)=$ 26,3. Hal tersebut, menunjukkan bahwa pekerjaan tidak mempunyai hubungan yang signifikan dengan persepsi masyarakat tentang pencemaran udara; 
artinya jenis pekerjaan masyarakat tidak mempengaruhi persepsi mereka tentang pencemaran udara. Nilai koefisien kontingensi sebesar 0,4931 mengungkapkan bahwa derajat hubungan yang kurat erat antara pekerjaan dengan persepsi masyarakat tentang pencemaran udara.

Pada Tabel 3, nilai $X^{2}{ }_{\text {hitung }}$ Hubungan penghasilan dengan persepsi masyarakat tentang pencemaran udara sebesar 24,271 lebih kecil daripada $\mathrm{X}_{\text {tabel }}^{2}(16 ; 0,05)=$ 26,3. Hal tersebut, menunjukkan bahwa penghasilan tidak mempunyai hubungan yang signifikan dengan persepsi masyarakat tentang pencemaran udara; artinya tidak ada perbedaan yang nyata antara tingkat penghasilan dengan persepsi masyarakat tentang pencemaran udara. Dengan kata lain, tingkat penghasilan seseorang tidak mempengaruhi persepsinya tentang pencemaran udara. Nilai koefisien kontingensi sebesar 0,5367 menunjukkan derajad hubungan yang kurang erat antara tingkat penghasilan dengan persepsi masyarakat tentang pencemaran udara.

Pada Tabel 3, nilai $\mathrm{X}^{2}$ hitung Hubungan jarak rumah dengan persepsi masyarakat tentang pencemaran udara sebesar 11,378 lebih kecil daripada $\mathrm{X}_{\text {tabel }}^{2}(8 ; 0,05)=$ 15,5. Hal tersebut, menunjukkan bahwa jarak rumah tidak mempunyai hubungan yang signifikan dengan persepsi masyarakat tentang pencemaran udara; artinya jauh dekatnya jarak rumah masyarakat dari PLTD tidak mempengaruhi persepsi mereka tentang pencemaran udara. Nilai koefisien kontigensi sebesar 0,3992 menunjukkan derajad hubungan yang kurang erat antara jarak rumah dengan persepsi masyarakat tentang pencemaran udara.

Pada Tabel 3, nilai $X^{2}$ hitung Hubungan lama tinggal dengan persepsi masyarakat tentang pencemaran udara sebesar 33,729 lebih besar daripada $\mathrm{X}_{\text {tabel }}^{2}(12 ; 0,05)=$ 21,0. Hal tersebut, menunjukkan bahwa lama tingal mempunyai hubungan yang signifikan dengan persepsi masyarakat tentang pencemaran udara; artinya perbedaan lama tinggal masyarakat di sekitar PLTD menyebabkan perbedaan persepsi mereka tentang pencemaran udara. Penelitian mengungkapkan lama tinggal antara satu sampai 10 tahun lebih peka daripada lama tinggal kurang dari satu tahun dan 10 tahun ke atas. Nilai koefisien kontingensi sebesar 0,5881 menunjukkan derajat hubungan yang cukup erat antara lama tinggal seseorang dengan persepsinya tentang pencemaran udara. Dalam hubungannya dengan kondisi udara di lingkungan tempat tinggal responden dengan perubahan-perubahan yang terjadi, ketika dilakukan analisis silang antara ubahan lama tinggal responden dengan perbandingan kondisi udara pada waktu responden pertama kali tinggal di tempat sekarang. Dari 60 responden yang mengetahui perbandingan kondisi udara di sekitar tempat tinggalnya, 42 resonden $(70,00 \%)$ menyatakan kondisi udara sekarang lebih kotor dibandingkan dahulu, dan 7 responden $(6,67 \%)$ menyatakan kondisi udara sangat kotor.

Pengetahuan responden tentang kebisingan dari PLTD Bitung adalah sebesar 96,67 \% atau 58 responden, walau pun pengetahuan tersebut sanat awam sifatnya, dan sebesar 3,33\% atau hanya 2 responden yang menjawab tidak mengetahui.

Persepsi (pemahaman) responden tentang kebisingan, sebanyak 32 responden $(53,33 \%)$ menjawab sangat bising, 17 responden $(28,33 \%)$ menjawab bising, $\quad 7$ responden $(11,67 \%)$ menjawab tidak tahu, 3 responden $(5,00$ $\%)$ menjawab tidak bising, dan 1 responden $(1,67 \%)$ menjawab sangat 
tidak bising. Penyebab kebisingan 60 responden (100, $00 \%)$ menjawab PLTD. Kebisingan pada jam-jam tertentu, sebanyak 10 responden $(16,67 \%)$ menjawab pada jam 06.00 - 12.00; 16 responden $(26,67 \%)$ menjawab pada jam $12.00-18.00 ; 30$ responden $(50,00 \%)$ menjawab pada jam 18.00 - 24.00, dan 4 responden $(6,66 \%)$ menjawab pada jam $00.00-06.00$.

Ketika ditanyakan adakah yang dirugikan dengan keberadaan PLTD yang menyebabkan pencemaran udara dan kebisingan, sebanyak 55 responden $(91,67$ $\%$ ) menjawab ya, dan hanya 5 responden $(8,33 \%)$ yang menjawab tidak. Mengenai pertanyaan adakah pihak yang dirugikan, sebanyak 60 responden $(100,00 \%)$ menjawab masyarakat, lainnya tidak ada. Hal tersebut, menunjukkan bahwa kesadaran masyarakat tentang kejadian pencemaran udara dan kebisingan sudah cukup tinggi.

Mengenai tindakan yang dilakukan responden, sebanyak 35 responden $(58,34 \%)$ menjawab diam saja atau pasrah, 20 responden $(33,33 \%)$ menjawab menutup jendela, dan 5 responden $(8,33$ $\%)$ menjawab melapor ke aparat. Dari hasil wawancara dengan beberapa tokoh masyarakat pada umumnya mengatakan mereka sudah banyak kali melapor kepada pemerintah, namun tidak ada tanggapan, sehingga kahirnya hanya pasrah saja.

Mengenai pertanyaan apakah PTLD yang menyebabkan pencemaran udara dan kebisingaan, mengganggu kesehatan masyarakat, 32 responden $(53,33 \%)$ menjawab sangat mengganggu, 17 responden $(28,33 \%)$ menjawab mengganggu, 7 responden $(11,67 \%)$ menjawab tidak tahu, 3 responden $(5,00$ $\%)$ menjawab tidak mengganggu, dan 1 responden $(1,67 \%)$ menjawab sangat tidak mengganggu.
Penyakit yang sering menimpa masyarakat, 29 responden $(48,33 \%)$ menjawab saluran pernapasan, 9 responden $(15,00 \%)$ menjawab gigi, 7 responden $(11,67 \%)$ menjawab kepala, 5 responden $(8,33 \%)$ menjawab diare, 4 responden $(6,67 \%)$ menjawab telinga dan gatal-gatal, dan 2 responden $(3,33 \%)$ menjawab mata. Hasil tersebut, diperkuat dengan hasil wawancara dengan seorang petugas kesehatan (mantri) yang membuka praktek di dekat PLTD mengatakan penyakit yang dominan, yaitu sekitar $60,00 \%$ menimpa masyarakat adalah saluran pernapasan seperti batuk, influensa. Mengenai pertanyaan penyebab penyakit yang sering menimpa masyarakat, 34 responden $(56,67 \%)$ menjawab asap PLTD, 13 responden $(21,67 \%)$ menjawab debu jalanan, 6 responden $(10,00 \%)$ menjawab asap kendaraan bermotor, 5 responden $(8,33 \%)$ menjawab masuk angin, dan 2 responden $(3,33 \%)$ menjawab asap rokok.

Mengenai pertanyaan bagaimana sikap masyarakat tentang PLTD yang ada di kompleks mereka, 34 responden $(56,67$ $\%)$ menjawab sangat tidak setuju, 14 responden $(23,33 \%)$ menjawab tidak setuju, 10 responden $(16,56 \%)$ menjawab tidak tahu, dan 2 responden $(3,33 \%)$ menjawab setuju.

Sarwono (1999), Soeryani, at.al. (2007), dan Soejono (2010) menyatakan faktor sosial ekonomi yang berhubungan dengan persepsi masyarakat, yaitu: umur, tingkat pendidikan, pekerjaan, dan penghasilan. Hasil perhitungan statistik dengan menggunakan analisis statistik Kai-Kuadrat (Chi-Square) (Siegel, 2005, dan Walpole, 2007) menunjukkan faktor sosial ekonomi yang berhubungan dengan persepsi masyarakat tentang kebisingan sumber energi diesel (PLTD Bitung dapat dilihat pada tabel 5 . 
Pada tabel 4, nilai $\mathrm{X} 2_{\text {hitung }}$ hubungan umur dengan persepsi masyarakat tentang kebisingan sebesar 18,978 lebih kecil daripada $\mathrm{X}_{\text {tabel }}^{2}(20 ; 0,05)=31,0$. Hal tersebut, menunjukkan bahwa umur tidak mempunyai hubungan yang signifikan dengan persepsi masyarakat tentang kebisingan; artinya faktor umur masyarakat tidak mempengaruhi persepsi mereka tentang kebisingan. Hasil penelitian menggungkapkan bahwa semua kategori umur sependapat bahwa sangat bising di kompleks mereka akibat PLTD. Nilai koefisien kontingensi sebesar 0,4902 menunjukkan derajad hubungan yang kurang erat antara umur seseorang dengan persepsinya tentang kebisingan.

Pada tabel 4 , nilai $\mathrm{X}^{2}{ }_{\text {hitung }}$ hubungan pendidikan dengan persepsi masyarakat tentang kebisingan sebesar 13,234 lebih kecil daripada $\mathrm{X}_{\text {tabel }}^{2} \quad(16 ; 0,05)=$ 31,0. Hal tersebut, menunjukkan bahwa tingkat pendidikan tidak mempunyai hubungan yang signifikan dengan persepsi masyarakat tentang kebisingan; artinya tingkat pendidikan masyarakat tidak mempengaruhi persepsi mereka tentang kebisingan. Hasil penelitian menggungkapkan bahwa dari 60 responden, ada 32 responden $(53,33 \%)$ yang terbagai pasa semua kategori tingkat pendidikan sependapat bahwa sangat bising di kompleks mereka akibat PLTD.

Nilai koefisien kontingensi sebesar 0,4251 menunjukkan derajad hubungan yang kurang erat antara tingkat pendidikan formal dengan persepsinya tentang kebisingan. Hal tersebut, menjelaskan bahwa tinggi rendahnya pendidikan formal seseorang tidak mempengaruhi persepsinya tentang kebisingan.

Pada Tabel 4, nilai $\mathrm{X}^{2}$ hitung hubungan pekerjaan dengan persepsi masyarakat tentang kebisingan sebesar 23,986 lebih kecil daripada $\mathrm{X}_{\text {tabel }}^{2} \quad(16 ; 0,05)=$ 26,3. Hal tersebut, menunjukkan bahwa pekerjaan tidak mempunyai hubungan yang signifikan dengan persepsi masyarakat tentang kebisingan; artinya jenis pekerjaan masyarakat tidak mempengaruhi persepsi mereka tentang kebisingan. Dengan kata lain, tidak ada perbedan yang nyata antara jenis pekerjaan responden dengan persepsinya tentang kebisingan. Nilai koefisien kontingensi sebesar 0,5344 menunjukkan derajad hubungan yang kurang erat antara pekerjaan dengan persepsi masyarakat tentang kebisingan.

Pada Tabel 4, nilai $\mathrm{X}^{2}{ }_{\text {hitung }}$ hubungan penghasilan dengan persepsi masyarakat tentang kebisingan sebesar 11,914 lebih kecil daripada $\mathrm{X}^{2}$ tabel $\quad(16 ; 0,05)=$ 26,3. Hal tersebut, menunjukkan bahwa penghasilan tidak mempunyai hubungan yang signifikan dengan persepsi masyarakat tentang kebisingan; artinya tinggi rendahnya tingkat penghasilan masyarakat masyarakat tidak mempengaruhi persepsi mereka tentang kebisingan. Dengan kata lain, tidak ada perbedan yang nyata antara tingkat penghasilan dengan persepsi masyarakat tentang kebisingan. Nilai koefisien kontingensi sebesar 0,5344 menunjukkan derajad hubungan yang kurang erat antara pekerjaan dengan persepsi masyarakat tentang kebisingan. Walau pun sesuai dengan hasil penelitian bahwa tingkat penghasilan masyarakat cukup berbeda, yang diasumsikan bahwa semakin tinggi tingkat pengahasilan seseorang akan semakin mampu membeli alat-alat peredam kebisingan. Nilai koefisien kontingensi sebesar 0,4070 menunjukkan derajad hubungan yang kurang erat antara tingkat penghasilan dengan persepsi masyarakat tentang kebisingan.

Pada Tabel 4, nilai $\mathrm{X}^{2}{ }_{\text {hitung }}$ hubungan jarak rumah dengan persepsi masyarakat tentang kebisingan sebesar 17,452 lebih besar daripada $X_{\text {tabel }}^{2}(8 ; 0,05)=15,5$. Hal 
tersebut, menunjukkan bahwa jarak rumah mempunyai hubungan yang signifikan dengan persepsi masyarakat tentang kebisingan; artinya jarak rumah masyarakat dari PLTD mempengaruhi persepsi mereka tentang kebisingan. Hasil penelitian mengungkapkan bahwa masyarakat yang rumahnya berjarak di bawah 100 meter dari PLTD berpersepsi negatif, artinya mereka semakin sangat tidak setuju dengan adanya kegiatan PLTD yang menimbulkan kebisingan di kompleks mereka. Nilai koefisien kontingensi sebesar 0,4747 menunjukkan derajad hubungan yang cukup erat antara jarak rumah dengan persepsi masyarakat tentang kebisingan. Pada Tabel 3.29, nilai $\mathrm{X}^{2}$ hitung hubungan lama tinggal dengan persepsi masyarakat tentang kebisingan sebesar 9,478 lebih kecil daripada
$X_{\text {tabel }}^{2}(12 ; 0,05)=21,0$. Hal tersebut, menunjukkan bahwa lama tinggal tidak mempunyai hubungan yang signifikan dengan persepsi masyarakat tentang kebisingan; artinya lama tinggal masyarakat di sekitar PLTD mempengaruhi persepsi mereka tentang kebisingan; artinya lama tinggal responden di kompleks PLTD tidak menyebabkan perbedaan persepsi mereka tentang kebisingan.

Nilai koefisien kontingensi sebesar 0,3693 menunjukkan derajad hubungan yang kurang signifikan antara lama tinggal dengan persepsi masyarakat tentang kebisingan. Malah ada kesan bahwa semakin lama masyarakat tinggal di sekitar PLTD, mereka semakin terbiasa dengan faktor kebisingan.

Tabel 4. Hubungan Faktor Sosial Ekonomi dengan Persepsi Masyarakat tentang Kebisingan

\begin{tabular}{|c|c|c|c|c|c|c|c|c|c|}
\hline \multirow{2}{*}{$\begin{array}{c}\text { Faktor } \\
\text { Sosial } \\
\text { Ekonomi }\end{array}$} & \multirow{2}{*}{ Kategori } & \multicolumn{5}{|c|}{$\begin{array}{c}\text { Persepsi Masyarakat } \\
\text { Tentang Kebisingan }\end{array}$} & \multicolumn{3}{|c|}{ Nilai } \\
\hline & & $\begin{array}{l}\mathbf{S} \\
\mathbf{B}\end{array}$ & $\begin{array}{l}\text { B } \\
\text { S }\end{array}$ & $\begin{array}{l}\mathbf{T} \\
\mathbf{H}\end{array}$ & $\begin{array}{l}\mathbf{T} \\
\mathbf{B}\end{array}$ & STB & $X^{2}{ }_{h t g}$ & $X^{2}{ }_{t b l} 0.05$ & KK \\
\hline \multirow{6}{*}{ Umur } & $<25$ & 3 & 0 & 0 & 1 & 0 & \multirow{6}{*}{$18.977^{\text {tn }}$} & & \multirow{6}{*}{0.4902} \\
\hline & $25-35$ & 15 & 4 & 1 & 1 & 0 & & & \\
\hline & $36-45$ & 8 & 9 & 5 & 1 & 0 & & 31.4 & \\
\hline & $46-55$ & 5 & 3 & 1 & 1 & 1 & & $\mathrm{db}=20$ & \\
\hline & $56-65$ & 1 & 1 & 0 & 0 & 0 & & & \\
\hline & $>65$ & 1 & 0 & 0 & 0 & 0 & & & \\
\hline \multirow{5}{*}{ Pendidikan } & SD & 2 & 0 & 0 & 0 & 0 & \multirow{5}{*}{$13.324^{\text {tn }}$} & \multirow{5}{*}{$\begin{array}{c}26.3 \\
\mathrm{db}=16\end{array}$} & \multirow{5}{*}{0.4251} \\
\hline & SLTP & 11 & 5 & 2 & 1 & 0 & & & \\
\hline & SLTA & 16 & 5 & 3 & 2 & 1 & & & \\
\hline & Akademi & 1 & 5 & 2 & 0 & 0 & & & \\
\hline & Universitas & 2 & 2 & 0 & 1 & 0 & & & \\
\hline \multirow{5}{*}{ Pekerjaan } & PNS/ABRI & 3 & 2 & 0 & 0 & 0 & \multirow{5}{*}{$23.986^{\mathrm{tn}}$} & \multirow{5}{*}{$\begin{array}{c}26.3 \\
\mathrm{db}=16\end{array}$} & \multirow{5}{*}{$0.5344^{+}$} \\
\hline & Karyawan & 12 & 5 & 3 & 1 & 1 & & & \\
\hline & Swasta & 12 & 7 & 3 & 0 & 0 & & & \\
\hline & Wiraswasta & 5 & 3 & 1 & 1 & 0 & & & \\
\hline & $\begin{array}{l}\text { Petani/Buruh } \\
\text { Pensiunan }\end{array}$ & 0 & 0 & 0 & 1 & 0 & & & \\
\hline \multirow{8}{*}{ Penghasilan } & $<100.000$ & 3 & 0 & 0 & 0 & 0 & \multirow{8}{*}{$11.914^{\mathrm{tn}}$} & \multirow{8}{*}{$\begin{array}{c}26.3 \\
d b=16\end{array}$} & \multirow{8}{*}{0.4070} \\
\hline & $100.000-$ & 10 & 7 & 5 & 2 & 0 & & & \\
\hline & 250.000 & 7 & 3 & 1 & 0 & 1 & & & \\
\hline & 251.000 - & 9 & 5 & 1 & 1 & 0 & & & \\
\hline & 350.000 & 3 & 2 & 0 & 0 & 0 & & & \\
\hline & 351.000 - & & & & & & & & \\
\hline & 500.000 & & & & & & & & \\
\hline & $501.000-1$ juta & & & & & & & & \\
\hline
\end{tabular}

Jurnal Frontiers Volume 1 Nomor 1, April 2018130

P-ISSN: 2621-0991 E-ISSN: 2621-1009 


\begin{tabular}{cccccccccc}
\hline Jarak & $<50 \mathrm{~m}$ & 17 & 1 & 1 & 1 & 0 & & & \\
Rumah & $50-100 \mathrm{~m}$ & 8 & 8 & 4 & 0 & 0 & $17.452^{*}$ & 15.55 & 0.4747 \\
& $>100 \mathrm{~m}$ & 7 & 8 & 2 & 2 & 1 & & $\mathrm{db}=8$ & \\
\hline \multirow{2}{*}{ Lama } & $<1 \mathrm{thn}$ & 6 & 2 & 0 & 0 & 0 & & & \\
Tinggal & $1-5 \mathrm{thn}$ & 10 & 5 & 4 & 2 & 1 & & 21.0 & \\
& $6-10 \mathrm{thn}$ & 4 & 4 & 2 & 1 & 0 & $9.478^{*}$ & $\mathrm{db}=12$ & 0.3693 \\
& $>10 \mathrm{thn}$ & 12 & 6 & 1 & 0 & 0 & & & \\
\hline
\end{tabular}

Keterangan:

\begin{tabular}{|c|c|c|c|c|}
\hline SB & Sangat Bising & $X^{2}$ & $=$ & Kai Kuadrat \\
\hline BS & Bising & KK & $=$ & Koefisien Kontigensi \\
\hline TH & Tidak tahu & & tn) & $=$ Tidak nyata dalam taraf 0,05 \\
\hline TВ & Tidak Bising & $*)$ & $=$ & Signifikan pada $p=0,05$ \\
\hline STB & Sangat Tidak Bising & $+)$ & $=$ & Derajat hubungan erat \\
\hline
\end{tabular}

\section{PENUTUP}

\section{Kesimpulan}

a. Kualitas udara untuk parameter $\mathrm{SO}_{2}$, $\mathrm{NO}_{2}, \mathrm{H}_{2} \mathrm{~S}, \mathrm{NH}_{3}$ dan $\mathrm{CO}$ menunjukkan bahwa seluruhnya berada di bawah ambang batas baku mutu kualitas udara ambien. Sedangkan debu pada titik A, $\mathrm{E}$, dan $\mathrm{J}$ berada di atas ambang batas baku mutu kualitas udara.

b. Tingkat kebisingan sebagai dampak dari kegiatan PLTD Bitung diperoleh bahwa di seluruh lokasi pengukuran pada jarak $100 \mathrm{~m}$ ke bawah telah melewati ambang batas baku mutu kebisingan yang diperbolehkan.

c. Faktor latar belakang sosial masyarakat, yaitu umur, dan lama tinggal dengan sumber pencemaran (PLTD) secara signifikan mempunyai hubungan dengan persepsi masyarakat tentang pencemaran udara. Demikian juga dengan jarak rumah dengan sumber kebisingan secara signifikan mempunyai hubungan dengan persepsi masyarakat tentang kebisingan.

\section{Saran}

a. Pemerintah diharapkan bertindak sebagai penyuluh tentang lingkungan yang efektif. Hal penting berikutnya yang perlu diperhatikan ialah masalah penataan kembali kawasan pemukiman dan kawasan industri. Dengan memperhatikan kelurahan Bitung Tengah sebagai pemukiman penduduk, maka sebaiknya PLTD berjarak minimal $100 \mathrm{~m}$ dari pemukiman penduduk.

b. Dalam upaya menurunkan tingkat kebisingan di kawasan pemukiman penduduk, hendaknya menanam pohon di kawasan PLTD, antara lain pohon bambu kuning (Bambusa vulgaris) dan pohon cemara laut (Casuarina equisetifolia). Tanaman tersebut, selain berfungsi sebagai peredam bunyi, juga dapat menambah keindahan (estetika).

\section{DAFTAR PUSTAKA}

Arikunto, S. 2004. Prosedur Penelitian. Bina Aksara. Jakarta.

Canter, L.W. 1997. Environmental Impact Asseeement. McGraw Hill Series in Water Resources and Environmental Engineering. McGraw-Hill Book Company. New York.

Siegel, S. 1995. Statistik Nonparametrik Untuk Ilmu-ilmu Sosial. Gramedia. Jakarta.

Soeryani, M. 1997. Lingkungan Sumber Daya Alam dan Kependudukan dalam 
Pembangunan. Universitas Indonesia Press. Jakarta.

Sudjana. 2006. Metoda Statistika. Tarsito. Bandung.

Tampang, B.L. 2012. Metodologi Penelitian. Konsep Dasar dan Penerapannya. LP2AI Unima. Manado.

Wardhana, W.A. 2004. Teknik Analisis Radioaktivitas Lingkungan. Andi Offset. Yogayakarta.

World Meteorological Organization. 1990. Urban Climate. Proc. of Symposium on Urban Climate and Building Climatology. Technical Note No. 108. Geneve, Switzerland. 